\title{
MULHERES NEGRAS EDUCADORAS NA REDE MUNICIPAL DE ENSINO DE CRICIÚMA: OS DESAFIOS PARA O ENFRENTAMENTO DO RACISMO E SEXISMO
}

\section{BLACK WOMEN EDUCATORS IN THE MUNICIPAL CRIMINAL EDUCATION NETWORK: THE CHALLENGES TO FACE RACISM AND SEXISM}

\author{
Gabriela de Abreu Ghisleri ${ }^{1}$ \\ Lucy Cristina Ostetto ${ }^{2}$
}

\begin{abstract}
RESUMO: A presente pesquisa objetiva refletir sobre narrativas de mulheres negras educadoras na Rede Municipal de Ensino de Criciúma identificando nas suas trajetórias os desafios enfrentados para inserção e permanência no campo educacional, bem como o enfrentamento na luta contra o racismo e o sexismo. Por meio de entrevista com quatro educadoras negras da Rede Municipal de Ensino de Criciúma, foi realizada uma análise qualitativa de natureza básica com o objetivo de compreender suas experiências na educação básica. Para tanto, dialogamos com Bispo (2012), Carneiro (2003), Crenshaw (2012), Jesus (2010), Brasil (2003) e da Lei $n^{\circ} 10.639 \backslash 03$, dispositivo legal regulador das Diretrizes Curriculares Nacionais para a Educação das Relações Étnico-Raciais e para o Ensino de História e Cultura Afro-Brasileira e Africana para a Educação Étnico-racial. Além da discussão a respeito do conteúdo legal, foram abordadas durante a análise questões referentes ao movimento feminista negro, às discriminações raciais sofridas pelas entrevistadas e as dificuldades para ingresso como docentes no campo educacional influenciada por estereótipos impostos pela sociedade brasileira sobre os negros. As educadoras entrevistadas acreditam que a educação é uma ferramenta de transformação capaz de construir uma sociedade mais justa e igualitária sem espaço para o racismo, o preconceito e a discriminação. Apontam que a trajetória para busca destes ideais fortalece uma luta social cujo resultado almejado faz com que qualquer desafio valha à pena.
\end{abstract}

PALAVRAS CHAVE: Educação. Escola. Feminismo negro. Mulheres negras. Narrativas.

ABSTRACT: This research has the purpose to reflect about the black women educators stories from the teaching chain in Criciuma. The paths and challenges, highlighting the challenges faced by black women to be insert and continue in the educational environment. Through interview with about four black women educators from Criciuma

\footnotetext{
${ }^{1}$ Graduanda Acadêmica do Curso de Pedagogia pela UNESC gabighisleri65 @ hotmail.com

${ }^{2}$ Orientadora Mestra em História pela UFSC. Professora dos Cursos de História e Pedagogia da UNESC. lco@unesc.net
}

Saberes Pedagógicos, Criciúma, v. 3, n³, Edição Especial 2019.- Curso de Pedagogia - UNESC 
teaching chain, it was made basic qualitative analyses in order to understand their experiences in the basic teaching field. It was spoken to Bispo (2012), Carneiro (2003), Crenshaw (2012), Jesus (2010), Brazil (2003) and the law number 10.639/03 and national curricular guidelines from basic education for the relation of the education racial ethnic and for the teaching about Afro Brazilian History and culture and African for the ethnic racial education. It was approached some issues about the black feminist movement,racial discrimination suffered by black educators and the difficulty to get inside the educational field, to win the stereotypes applied by the society about the Brazilian black people. The interviewees believe that the education is a tool to construct a fairer society and egalitarian, where there is no more space for the racism, prejudice and discrimination. The way to reach these ideals strengthen a social fight witch the result aspired makes any challenge worth it.

KEYWORDS: Education. School. Black feminism. Black women. Narratives.

\section{A ESCOLA COMO PONTO DE PARTIDA}

A construção da sociedade brasileira tem em seus pilares histórias de violência, opressão e abuso. Aos olharmos especificamente uma das mais violentas, percebemos na escravidão, a existência de uma instituição responsável pela disseminação de prejuízos sociais perpetrados até os dias atuais. Em um país onde ainda se pode falar na supremacia de uma raça em detrimento de outra, os efeitos da escravidão determinam e moldam a história da mulher negra até hoje.

Refletindo sobre a história desta mulher, cujo teor devemos ressalvar ser diferente da história da mulher branca (JESUS, 2010), buscamos compreender, sob o olhar de quatro educadoras negras, os efeitos da mazela social do racismo e da discriminação trazidos pelo regime de escravidão, especificamente no acesso destas ao sistema de ensino da Rede Pública Municipal de Criciúma.

É cabível, portanto, questionar os efeitos da distinção entre iguais em razão da sua raça e de seu gênero, particularmente quando constatada in loco situações de preconceito e discriminação contra educadoras negras dentro do ambiente escolar. Para tanto, apresenta-se como tema central da pesquisa as "Mulheres negras educadoras na Rede Municipal de Ensino de Criciúma: Os desafios para os enfrentamentos do racismo e sexismo".

Saberes Pedagógicos, Criciúma, v. 3, n³, Edição Especial 2019.- Curso de Pedagogia - UNESC 


\section{SABERES PEDAGÓGICOS}

Revista do Curso de Graduaçāo de Pedagogia - Unesc

ISSN 2526-4559

A existência de preconceito entre pessoas em razão da cor de sua pele nos leva a questionar como em pleno século XXI, ainda temos uma sociedade permeada por tanto preconceito. Igualmente arguimos como pode haver a perpetuação do racismo dentro de organizações escolares em despeito da capacidade intelectual do indivíduo. Se em parte o conteúdo curricular das aulas de História e Filosofia narra trajetórias de orgulho e luta enfrentadas pelos negros, como ainda o preconceito é tão manifesto dentro do ambiente escolar? Como esta mesma história pode ser narrada por educadoras brancas ao mesmo tempo em que muitas destas demonstram parcela de preconceito contra educadoras negras? Qual a amplitude deste problema e como podemos utilizar esta experiência para repensarmos as relações étnico raciais nas escolas colocando em prática uma pedagogia antirracista, fundamentada em uma lei $(10.639 \backslash 03)^{3}$ que também objetiva enfrentar e transformar esta realidade escolar?

A percepção da existência de preconceito e racismo dentro do ambiente escolar em oposição ao que preceitua os fundamentos da educação, torna relevante a pesquisa sobre a experiência de docentes negras na rede Municipal de Criciúma es pecificamente no que tange às relações étnico raciais perpassadas pelo racismo e preconceito vivenciados na escola. Neste contexto, são norteadoras as seguintes problematizações: Quais as dificuldades encontradas pelas educadoras negras no ambiente escolar devido ao seu pertencimento racial? Como as educadoras negras lidam com as dificuldades encontradas em relação ao preconceito e racismo? Como a educadora negra luta por seu espaço no ambiente escolar, e de que forma lida com o preconceito quando acontece? De que forma enfrentam essas dificuldades e como estas questões interferem em sua carreira profissional. É mais que urgente refletirmos sobre estas questões, pois compreendemos com Jesus (2010, p. 481-482) que,

Ser mulher negra é experimentar a inter-relação entre sexismo e racismo, e nessa dinâmica, as mulheres buscam formas de organização que as fortaleçam para a tarefa de reescrita de suas histórias, considerando os seus contextos de luta pela cidadania, visando romper, assim, com as estruturas do universalismo ocidental que as inferiorizam. E até mesmo a invisibilidade dentro dos movimentos feministas e negros, onde suas demandas específicas, originada da inter-relação

\footnotetext{
${ }^{3}$ A Lei Federal no $10.639 \backslash 03$ sancionada em março de 2003, que alterou a Lei 9394\1996, estabeleceu a obrigatoriedade o ensino da história e cultura afro-brasileira e africana em todas as escolas, públicas e particulares, do ensino fundamental até o ensino médio.
}

Saberes Pedagógicos, Criciúma, v. 3, n³ 3, Edição Especial 2019.- Curso de Pedagogia - UNESC 


\section{SABERES PEDAGÓGICOS}

Revista do Curso de Graduaçāo de Pedagogia - Unesc

ISSN $2526-4559$

entre gênero e raça, não são pautadas, como se toda mulher fosse branca e todo negro fosse homem.

Para tanto, o presente artigo foi organizado em três blocos. No primeiro discutimos o surgimento do movimento feminista negro e a trajetória da luta das mulheres negras brasileiras. Num segundo analisamos o ingresso da mulher negra no mercado de trabalho em relação ao espaço educacional, de modo a conhecer quais foram os desafios enfrentados para extinção pela invisibilidade destas mulheres em razão de seu fenótipo, a luta antirracista. Em seguida trazemos a análise das entrevistadas com quatro educadoras negras que lecionam na Rede Municipal de Ensino de Criciúma relataram suas trajetórias, discriminações, dificuldades e lutas no campo educacional brasileiro. Para a escrita desse artigo dialogamos com Bispo (2012), Carneiro (2003), Crenshaw (2012), Jesus (2010), Brasil (2003) visto que estes abordam temas referentes às conquistas da mulher negra, ao movimento feminista negro e sobre a Lei $\mathrm{n}^{\circ} 10.639 \backslash 03$.

\section{FEMINISMO NEGRO COMO LUGAR DE LUTA}

O feminismo negro começou a ganhar espaço no cenário brasileiro no ano de 1985 com o movimento de mulheres que buscavam por sua voz e respeito em uma sociedade dominada pelo poder masculino. Segundo Bispo (2012) a história das mulheres negras no Brasil permanece mascarada, camuflada e descaracterizada nos espaços midiáticos e nas academias euro referenciadas de formação cristã e heterossexual. $\mathrm{O}$ movimento feminista negro começa a ganhar força no Brasil a partir do momento em que se observa o movimento feminista organizado por mulheres brancas. Ao se identificar que o mesmo não contemplava as pautas, lutas e especificidades das mulheres negras, referido movimento tornou-se incompatível à luta das mulheres negras por contemplar somente estudos sobre mulheres brancas, de classe média e intelectualizada (AZEREDO, 1994).

Segundo Soares (2004) o feminismo negro engloba teoria, prática e ética, tomando as mulheres como sujeitos históricos da transformação da sua própria condição social. Propõe que as mulheres negras possam transformar a si mesmas e o mundo a partir de suas experiências em contraponto aos diferentes estereótipos construídos ao longo da

Saberes Pedagógicos, Criciúma, v. 3, n³, Edição Especial 2019.- Curso de Pedagogia - UNESC 
história, entre eles o de que seus corpos e vidas não tem valor e que deviam permanecer em espaços subalternizados.

De acordo Bispo (2012, p.12):

As mulheres negras que decidiram dedicar suas vidas ao combate das várias formas de opressão, pelo caminho do ativismo político, experimentaramlconstruíram formas múltiplas de existir, enquanto negras e como mulher.

Compreender a sua condição de mulher negra para transformar e valorizar sua própria condição social foi o primeiro passo do movimento feminista negro.

Nesse aspecto Giacomini (1988, p. 9) afirma que:

Participantes do movimento negro e feminista, as mulheres negras, conscientes da importância de seu papel na história, visam a desmascarar situações de conflito e exclusão. Com isso, não só contribuíram para a conquista de visibilidade como sujeitos políticos, perante esses movimentos e a sociedade, como também construíram um curso próprio através da constituição do movimento autônomo de mulheres negras. Com isso, lutaram e lutam para garantir a subsistência, direitos sociais e políticos, e qualidade de vida para si, seus familiares e para a comunidade. Explicitamente, a agenda política das mulheres negras transcende as questões de gênero, abarcando o combate ao racismo, à discriminação e ao preconceito racial.

O feminismo negro possibilitou que se iniciassem discussões para defesa e luta por questões de raça, classe, gênero, politica, discriminação racial e empoderamento da mulher. Para Collins (2001 apud BAIRROS, 1995, p. 460), um dos objetivos do feminismo negro é resistir à opressão, sua prática e as ideias que a justificam. Se a intersecção da opressão não existisse, o pensamento feminista negro e similares conhecimentos oposicionistas seriam desnecessários. Cabe portanto à mulher negra lutar para defender-se da opressão imposta, valorizando sua história, sua cultura e experiências em um cenário racializado construído ao longo da história brasileira.

Neste sentido, Carneiro (2003, p. 25) afirma que:

Ao politizar as desigualdades de gênero, o feminismo transforma as mulheres em novos sujeitos políticos. Essa condição faz com esses sujeitos assumam, a partir do lugar em que estão inseridos, diversos olhares que desencadeiam processos particulares subjacentes na luta de cada grupo particular.

Saberes Pedagógicos, Criciúma, v. 3, n³, Edição Especial 2019.-- Curso de Pedagogia - UNESC 


\section{SABERES PEDAGÓGICOS}

Revista do Curso de Graduaçāo de Pedagogia - Unesc

ISSN $2526-4559$

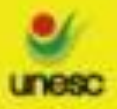

This nuiget

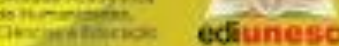

O feminismo negro potencializa a luta contra as múltiplas violências enfrentadas cotidianamente por mulheres negras colocando-as como sujeitos de direitos. O movimento parte das experiências perpassadas pelo enfrentamento do combate à violência e desigualdades por muito tempo naturalizadas, silenciadas e invisíveis à sociedade.

É importante compreendermos a interseccionalidade que abarca a questão de raça, gênero e classe como marcadores sociais interligados, produtores de múltiplas violências que os atravessam. De acordo com Crenshaw (2012), é preciso compreender mutuamente e não de uma maneira excludente a discriminação racial que afeta as mulheres em sentido lato sensu e a discriminação de gênero que afeta as mulheres negras.

As mulheres negras enfrentam cotidianamente tanto a discriminação racial como o sexismo. São duplamente privadas de seus direitos humanos seja por serem mulheres, seja por serem mulheres negras, de modo a tornarem-se mais vulneráveis a todo e qualquer tipo de violência. Com isso o maior desafio da interseccionalidade segundo Crenshaw (2012) é de que as mulheres negras devem ser duplamente protegidas. Em um primeiro momento devem ter proteção contra discriminação de gênero assim como as mulheres brancas. Aliada à proteção do gênero, terem resguardados seus direitos contra a discriminação racial não experimentada pelas mulheres brancas.

Como espaço de acolhimento e luta destas mulheres, o feminismo negro possibilita o enfrentamento da discriminação racial, da vergonha, do medo, do desrespeito dentre outras barreiras que impossibilitam às mulheres a conquista de seus direitos. Como consequência reconfigura-se o que mutuamente Bairros (1995) chama de um mosaico que só pode ser entendido em sua multidimensionalidade. Necessário portanto:

Resignificar as experiências de ser mulher negra a partir das questões de raça, gênero, ancestralidade, tradição, cultura, memórias, experiências, lutas e heterogeneidades como um conjunto de propósitos e ideias num mosaico que acolhe a multidimensionalidade de seus direitos, fazeres e saberes (BISPO, 2012, p. 4).

De acordo com o ponto de vista feminista, não existe uma identidade única, pois a experiência de ser mulher se dá de forma social e historicamente determinada, perpassada pelos marcadores sociais que as definem dentro de suas próprias particularidades (BAIRROS, 1995). A visão da mulher negra é aquela que desafiou as

Saberes Pedagógicos, Criciúma, v. 3, n³, Edição Especial 2019.- Curso de Pedagogia - UNESC 
ideias hegemônicas da elite masculina branca trazendo uma expressão da consciência sobre a intersecção de raça, classe e gênero.

De acordo com Collins (2001 apud BAIRROS, 1995, p.463).

[...] o pensamento feminista negro seria então um conjunto de experiências e ideais compartilhadas por mulheres afro americanas que oferecem um ângulo particular de visão do eu da comunidade e da sociedade ele envolve interpretações teóricas da realidade de mulheres negras por aqueles que a vivem.

Segundo Bispo (2012) as mulheres negras no Brasil passaram por experiências atravessadas pela escravização, pela memória ancestral, pela afirmação ao pertencimento étnico-cultural e da resistência à dominação e opressão as quais viveram e ainda vivem sem que estas tenham sido ouvidas, permanecendo assim não reconhecias como sujeitos de direitos.

Para isso Collins (2001 apud BAIRROS, 1995, p.7) reforça a importância de ouvir e documentar as experiências das mulheres negras para historicizá-las:

\begin{abstract}
Se nos meios acadêmicos brasileiro há um vazio, um silenciamento, um anonimato em relação a história das mulheres negras, isso não significa que elas, bem como sua história não existam. Embora seja inquestionável sua existência, estão, no entanto, submersas sob as regras das experiências etnoleurolcentricas. Assim, as memorias da população negra estão ai para serem ouvidas, contadas, registras, transmitidas. É o que alguns intelectuais e ativistas negras afirmam quando dizem que, nossos textos principais são nossas experiências.
\end{abstract}

Neste sentido é preciso reconhecer a importância do feminismo negro no Brasil como uma ferramenta de luta e afirmação das experiências das mulheres negras haja visto que o movimento alavanca as experiências destas mulheres para fora do anonimato e do esquecimento criando novas e orgulhosas memorias e histórias. No entanto, a concretude destas ideias somente será palpável se as mulheres negras não estiverem submersas em regras e modelos que não dizem respeitos às suas vidas. Desta forma, será possível escrever um novo capitulo para história destas mulheres, as colocando como sujeitos protagonistas na luta por igualdade de direitos.

\title{
3 A EDUCAÇÃO BRASILEIRA TAMBÉM É LUGAR DE MULHERES NEGRAS
}

Saberes Pedagógicos, Criciúma, v. 3, n³, Edição Especial 2019.- Curso de Pedagogia - UNESC 
Durante o período colonial no Brasil a sociedade era escravocrata, conservadora e excludente, meninas e mulheres negras eram designadas para o trabalho escravo lhes sendo negado o acesso à educação básica, tanto quanto as meninas e mulheres brancas e indígenas.

Desse modo, o não lugar dos negros na sociedade brasileira foi o fator essencial para que não lhes fossem concedidos direitos básicos, como por exemplo, o direito à educação e saúde. No caso das mulheres negras, tal fato se estendia para o âmbito doméstico, pois não podiam sequer criar seus filhos porque para sobreviver precisavam trabalhar como empregadas domésticas e ou babás, cuja função principal era a criação dos filhos das mulheres brancas, da classe média, que lutavam pela sua emancipação política e social (HENRIQUE, 2017, p. 154).

Situação parecida, identificamos em Hooks (2014, p. 464), ao descrever sobre as mulheres negras nos EUA:

O enorme espaço que o trabalho ocupa hoje na vida das mulheres negras segue um padrão estabelecido nos primeiros dias da escravidão. Como escravas o trabalho compulsório obscurecia todos os outros aspectos da existência das mulheres. Parece, pois que o ponto de partida para uma investigação da vidas das mulheres negras sob a escravidão seria uma avaliação de seus papeis como trabalhadoras.

Sua reflexão também se aplica ao Brasil, visto que nosso passado também foi construído pelas mãos destas mulheres por mais de 370 anos de escravidão. Ainda hoje a visão que sociedade brasileira tem sobre os espaços que devem ser ocupados pelas mulheres negras é marcada por discriminações e estereótipos naturalizados que se ligam ao papel de serviçal, herança do racismo e sexismo que vinculam esta mulher a um espaço e uma ocupação, qual seja, como doméstica em casa de famílias da elite brasileira. Mas, contrariando esta lógica, através da luta e da resistência, as mulheres negras entram na educação, campo esse anteriormente ocupado apenas por mulheres brancas de classe média. Cita Jesus (2010, p. 484) que:

Ao ocupar o espaço de representante do saber formal, as professoras negras rompem com um dos estereótipos criados sobre o negro brasileiro, o de que ele não tem capacidade intelectual. As identidades das profissionais da educação interagem, se formam e se transformam no decorrer de suas trajetórias.

Homens e mulheres que cotidianamente enfrentam situações de racismo, encontram na educação um espaço de acolhimento. É possível também notarmos o 
impacto da relação com a família, a participação em movimentos sociais e em outros espaços não formais de educação no luta contra a discriminação (JESUS, 2010).

De acordo com Carneiro (2003, s/p):

[...] é mister apontar que os ganhos obtidos pela luta feminista no mercado de trabalho. Malgrado se constituírem em grandes avanços, não conseguiram dirimir as desigualdades raciais que obstaculizam maiores avanços para as mulheres negras nessa esfera. Sendo assim, as propostas universalistas da luta das mulheres não só mostram a sua fragilidade, como a impossibilidade de as reivindicações que daí advêm, tornarem-se viáveis para enfrentar as especificidades do racismo brasileiro.

Como elucida Carneiro (2003) é crescente o número de mulheres negras na indústria e serviços modernos, deixando de ocuparem setores tomadores somente de mão de obra menos qualificada. A mulher negra passa a ter agora oportunidade para buscar sua qualificação profissional nas instituições de ensino superior e profissionalizantes. Isto porque, como já falamos,

\begin{abstract}
$\mathrm{Na}$ sociedade brasileira, o lugar dos homens e mulheres negro nunca foi à escola, mas a lavoura, na casa grande, na senzalas, nas ruas ou quando rebelde, na prisão. Assim, os direitos dos negros, em especial, das mulheres negras á educação no Brasil foi fruto de lutas travadas pelos movimentos negros. As lutas das mulheres negras pela educação no Brasil, tendo como pressuposto que a educação da mulher negra foi preterida pelo poder público e pela sociedade, no interior da própria classe trabalhadora e que somente foi possível pela prossecução das ações afirmativas. (HENRIQUES, 2017, p.153).
\end{abstract}

O feminismo negro serviu como sustentação e forneceu embasamento para luta das mulheres negras na busca de seu espaço na sociedade. $O$ fortalecimento deste movimento contribuiu para conquista da Lei Federal n $n^{\circ} 10.639 \backslash 03$ sancionada em março de 2003. A diretriz instituiu a obrigatoriedade do ensino da História da África e dos africanos no currículo escolar do ensino fundamental e médio. O principal objeti vo da lei é dar visibilidade á contribuição dos negros na construção e formação da sociedade brasileira, bem como ser um instrumento na luta antirracista (BRASIL, 2003).

Espera-se que a partir desta nova diretriz, a cultura africana seja abordada assim como a contribuição dos negros para sociedade brasileira entre outros aspectos anteriormente não integrantes do currículo escolar. Começa então a educação a caminhar 
para se tornar plural dando voz para temas e sujeitos esquecidos e desvalorizados ao longo do tempo. Assim a lei se coloca como:

[...] politicas de ações afirmativas, isto é, de politica de reparações, e de reconhecimento e valorização de sua história, cultura, identidade. Trata, ele, de politica curricular, fundada em dimensões históricas, sociais, antropológicas oriundas da realidade brasileira, e busca combater o racismo e as discriminações que atingem particularmente os negros. (BRASIL, 2003, p. 498).

Essa mudança na educação brasileira está apenas no começo, precisa ir além da escola para que a mudança aconteça de maneira significativa. De acordo com Brasil (2003) a mudança acontecerá de maneira total quando houver trabalhado em conjunto e de articulação entre processos educativos escolares, políticas públicas, movimentos sociais posto que as mudanças éticas, culturais, pedagógicas e politicas nas relações étnico-raciais não se limitam apenas à escola. É indispensável o apoio de todos os indivíduos para que a mudança na educação aconteça passando não ser apenas um problema das instituições de ensino, mas um problema de todos da sociedade.

O movimento negro e o movimento feminista negro entre outros movimentos no Brasil abraçaram a causa da diversidade encontrada no ambiente escolar e fora dele. Tais movimentos lutam e buscam recursos para defender essa causa com o propósito de incluir todos na educação e história brasileira. Defendem também que os negros precisam ser valorizados e sua história contada de maneira aprofundada para que todos consigam entender a importância desse povo e de suas lutas para a formação da sociedade brasileira.

Para isso,

Precisa, o Brasil, país multi-étnico e pluricultural, de organizações escolares em que todos se vejam incluídos, em que lhes seja garantido o direito de aprender e de ampliar conhecimentos, sem ser obrigados a negar a si mesmo, ao grupo étnico\racial a que pertencem e a adotar costumes, ideias e comportamentos que lhe são adversos. E estes, certamente, serão indicadores da qualidade da educação que estará sendo oferecida pelos estabelecimentos de ensino de diferentes níveis. (BRASIL, 2003, p. 503).

Assim a Lei $10.639 \backslash 03$ e o feminismo negro se colocam como uma ferramenta de luta na construção de uma sociedade mais justa, que oportunize e respeite a voz e o espaço do outro a fim de concretizar o que se chama de igualdade racial (BRASIL, 2003).

Saberes Pedagógicos, Criciúma, v. 3, n³, Edição Especial 2019.-- Curso de Pedagogia - UNESC 


\section{SABERES PEDAGÓGICOS}

Revista do Curso de Graduaçāo de Pedagogia - Unesc

ISSN 2526-4559

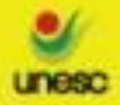

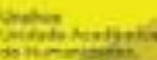

\section{AS LUTAS E ENFRENTAMENTOS DE EDUCADORAS NEGRAS}

A pesquisa foi realizada por meio de entrevistas, tendo como público alvo educadoras negras da Rede Municipal de Criciúma. Mediante análise qualitativa de natureza básica, objetivou-se entender o que é ser mulher negra na educação básica. A pesquisa em questão constituiu-se como semiestruturada de caráter exploratório com o intuito de relatar e entender as experiências e possíveis preconceitos encontrados por essas mulheres na docência. Conforme Gil (2007), a pesquisa é um processo lógico e organizado por problemas propostos, formada por diversas partes que vão desde a definição do problema até os resultados.

Não obstante a realização das entrevistas, a presente pesquisa é compreendida também por fundamentação teórica, por meio de pesquisa bibliográfica, que segundo Gil (1999) enobrece o trabalho por constituir uma rede muito maior do que o pesquisador poderia ter contato direto.

A pesquisa de campo foi realizada em escolas públicas localizadas no Município de Criciúma. Para realização foram convidadas dez educadoras negras. Deste grupo, apenas quatro concordaram em participar da pesquisa, as quais denominamos de Hauça, Jeje, Nagô e Iourubá em alusão a alguns povos africanos que contribuíram para formação da sociedade brasileira. O convite para participação da pesquisa ocorreu após breve explicação sobre a importância do conteúdo proposto e da necessidade de compreensão das experiências e possíveis preconceitos vivenciados pelas educadoras negras em sua trajetória no campo educacional brasileiro. Como instrumento de coleta de dados foi utilizada entrevista com perguntas referentes às narrativas sobre ser mulher negra na educação básica brasileira, seu conhecimento sobre o movimento feminista negro e a importância do mesmo e como as educadoras negras abordam a Lei $n^{\circ} 10.639 \backslash 03$ na sala de aula e a importância da Lei na luta contra a discriminação racial e o preconceito encontrado no Brasil.

Não é possível observar uma pessoa e determinar prontamente a posição que ocupa na sociedade ou em que medida está integrada no modo de vida urbano. Nesses casos, torna-se necessário operacionalizar esses conceitos ou variáveis,

Saberes Pedagógicos, Criciúma, v. 3, n³, Edição Especial 2019.- Curso de Pedagogia - UNESC 
ou seja, torná-los passíveis de observação empírica e de mensuração. Para tanto será necessário primeiramente defini-lo teoricamente (GIL, 2007, p.113).

Das quatro educadoras entrevistadas, Hauça, Jeje e Nagô comentaram que a escolha da profissão partiu de "vocação" ou desejo de ensinar o próximo. Iourubá por sua vez, relatou que na época morava em um município pequeno tendo só duas opções de curso, optando pelo Magistério. Todas as educadoras tiveram o apoio de familiares na escolha da profissão e enfrentaram dificuldades de frequentar as aulas em decorrência de suas ocupações.

Os desafios encontrados nessas trajetórias permitem que elas lancem um olhar sobre os seus papéis enquanto educadoras, traçando caminhos para uma educação emancipatória que problematiza a diversidade para assim entender as relações de poder que tentam manter as desigualdades (JESUS, 2010, p.485).

A entrevistada Jeje relatou que trabalhava na lavoura durante o dia e que após a jornada de trabalho necessitava percorrer aproximadamente $4 \mathrm{~km}$ à pé até a instituição de ensino para frequência no curso de Magistério. Por não possuir condições de retornar até sua residência necessitava realizar sua higiene pessoal em rio próximo à lavoura. Tais adversidades relatadas não permitiram que a educadora deixasse de frequentar assiduamente suas aulas.

Todas as quatro educadoras negras tem formação em cursos de Magistério e foram graduadas pela FUCRI/FACIECRI (hoje UNESC) nas décadas de 70, 80 e 90.

\footnotetext{
Referindo-se a esta capacidade, em tais circunstâncias, o negro escravizado devia reagir instintivamente ao terror, à dor, à flagelação e à prisão, mas também deveria encontrar respostas criadoras que lhe permitissem preservar sua própria cultura. O processo histórico da entrada das mulheres na carreira docente, assim como a universalização do acesso à escolarização, vem acompanhado da desvalorização e precarização desta carreira, (JESUS, 2010, p.481).
}

A entrada no campo educacional, como relatado por Jeje, foi de muita luta contra uma sociedade racista que mascarava sua capacidade intelectual e de ensinar o próximo. Quando questionadas se experimentaram preconceitos raciais na sua vida particular, as respostas foram afirmativas, mas não quiseram relatar quais foram as ofensas sofridas, exceto Hauça que relata com muita clareza as ofensas sofridas que 
marcaram sua trajetória.

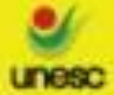

As pessoas me chamavam de negrinha, cabelo de Bombril, macaca, sujeira e quando eu era pequena no ensino fundamental as crianças me mandavam tomar banho com água sanitária para ver se eu ficava branca. Tudo isso marcou muito a minha vida hoje não passo por esses xingamentos, mas em alguns lugares que frequentei e frequento as pessoas me olham torto por eu ser uma mulher negra. Como uma vez fui em um restaurante que o garçom perguntou se eu não sabia que aquele lugar era caro e eu não teria dinheiro para pagar eu deveria ir para casa comprar um pizza de mercado e deixar o lugar livre para outra pessoa que poderia pagar para estar naquele lugar. Levantei da mesa e fui para casa me sentindo um lixo.

Historicamente, a mulher negra não é respeitada pela sociedade, estando sujeita ao preconceito e discriminação que desde muito cedo talha a perspectiva de sua vida. Segundo Jesus (2010, p. 480).

Saber-se negra ou negro geralmente faz com que a pessoa carregue sentimentos de negação, desde a infância, já que às imagens de beleza e de prestígio veiculadas pela mídia, pelas escolas e por outros aparelhos ideológicos, são distantes das características estéticas das pessoas negras.

As educadoras entrevistadas afirmaram que o feminismo negro é "ponte" para se obter igualdade racial na sociedade brasileira em uma batalha árdua a ser travada todos os dias visando o alcance de resultados significativos. Todas as educadoras relatam que conhecem o movimento feminista negro, contudo, Iourubá relatou com maior propriedade o assunto, descrevendo que conheceu o movimento há pouco mais de dois anos através da internet e busca manter-se atualizada.

O feminismo negro ajuda e ajudou muitas mulheres como eu a buscar e lutar pelos nossos direitos na sociedade brasileira, garantindo espaços que antes já seriam ocupados por mulheres iguais a mim negras. A sociedade via a gente como coitadas e pensavam que a gente servia apenas para servir os ricos. Junto com o movimento feminista negro estamos mostrando que podemos ocupar qualquer cargo na sociedade brasileira por que temos os mesmos potenciais que uma pessoa branca teria. Mas, não devemos espera os outros buscarem esses direitos por nos negros devemos lutar cada dia mostrando nosso potencial e orgulho da nossa história. Assim podemos buscar uma sociedade onde a igualdade e os direitos sejam dados a todos independente de sua cor ou classe social.

O feminismo negro, segundo o relato de Iourubá, é fundamental para encorajar mulheres que por muito tempo estiveram à mercê da sociedade brasileira, subjugadas pela Saberes Pedagógicos, Criciúma, v. 3, n³, Edição Especial 2019.- Curso de Pedagogia - UNESC 
discriminação racial e opressão de sua raça, à partirem em busca de mudança desta realidade. Segundo Jesus (2010) ao ocupar o espaço de representante do saber formal, as professoras negras rompem com um dos estereótipos criados sobre o negro brasileiro, o de que ele não tem capacidade intelectual. Com isso o feminismo negro contribui para mulheres negras conquistem espaços, inclusive na educação básica.

As educadoras relataram que a entrada na educação foi difícil por diversos motivos, predominando os obstáculos encontrados por serem negras.

Extraímos da narrativa de Nagô a seguinte colocação:

Ser negra torna tudo um pouco mais difícil às vezes eu pensava que cor da pele definia sim o caráter da pessoa, eu tinha que sempre mostra o meu potencial de poder está e trabalhar na educação como qualquer mulher branca teria. Pensava como eu sou negra não tenho condições de ensinar outra pessoa será. Por diversas vezes quase me entreguei ao pensamento cruel da sociedade pensando em desistir da minha carreira educacional, hoje acredito que fiz a escolha certa de seguir em frente e acreditar em mim mesmo sabendo que posso fazer tudo o que eu quero e tenho vontade por que também tenho meus direitos.

Todas as educadoras entrevistadas pensaram em algum momento desistir de sua profissão diante da imposição de pensamentos negativos e ofensas racistas. Esta constante negativação colocou em dúvida a visão das educadoras a respeito de seu real potencial intelectual, tornando a autoestima das mesmas fragilizadas por uma cultura permeada de pré-julgamentos, muitas vezes incapaz de reconhecer nestas profissionais indivíduos atuantes na busca de uma sociedade mais igualitária. A entrevistada Hauça aponta que boa parte das discriminações sofridas foi dirigida diretamente por pais ou responsáveis dos alunos ao afirmarem que uma educadora "negra e pobre nunca poderá ensinar ninguém, deveria estar na senzala e não na escola".

De acordo com Jesus (2010, p. 484),

Somente através das narrativas das professoras, é possível notar o quanto a relação com a família, trajetória escolar, participação em movimento social e em outros espaços não formais de educação se configuram em espaços de formação e de (re)construção de suas identidades e da formação docente.

No tocante à educação e formação docente, quando perguntado sobre a conquista da Lei Federal 10.639 \03, sancionada em março de 2003, as educadoras

Saberes Pedagógicos, Criciúma, v. 3, n³, Edição Especial 2019.- Curso de Pedagogia - UNESC 
enxergam na norma uma grande conquista para educação brasileira. Reconhecem que através desta lei foi ampliado o acesso dos os alunos do ensino fundamental e médio à história e a importância dos negros no Brasil.

Em relato, Jeje destaca:

\begin{abstract}
A Lei n ${ }^{\circ} 10.639 \backslash 03$ é uma grande conquista para nós negras e negros brasileiros, através dessa lei nossas crianças e adolescentes poderão estudar sobre a importância do nosso povo na construção da história brasileira. Essa lei já está presente nas escolas de educação básica mais precisa ainda ser trabalhada e melhor valorizada na educação como peça fundamental da história do Brasil. Cabe não só aos governantes a introduzir essa nova proposta na educação, mais os professores que também são ferramentas principais para que os alunos conheçam essa "nova" história do Brasil e a importância desse conhecimento para sua formação dos alunos. Com essa nova visão dentro da sala de aula será bem mais fácil para combater o racismo e as discriminações raciais na sociedade brasileira devido ter mais indivíduos conscientes da importância dos negros para história do Brasil. A aplicação dessa lei é um processo lento e continuo que deve ter o envolvimento de todos para construir uma sociedade mais justa.
\end{abstract}

As educadoras entrevistadas acreditam que a Lei $\mathrm{n}^{\circ} 10.639 \backslash 03$ está sendo aplicada nas escolas de educação básica brasileira. Não obstante, concordam haver necessidade de maior empenho dos profissionais da educação e da comunidade em geral para que haja uma maior valorização da diretriz. Para que esta valorização ocorra, segundo Brasil (2003) é preciso trabalhar com uma nova proposta de educação que, de acordo com as entrevistadas já é perceptível. Ressaltam que a introdução da Lei $\mathrm{n}^{\circ}$ 10.639\03 nas escolas isoladamente não traz garantias de diminuição do racismo e as discriminações raciais no ambiente escolar. Neste sentido discorre Nagô:

\footnotetext{
Mesmo com a Lei em vigor nas escolas brasileiras não é a garantir do racismo e discriminações raciais não fazerem parte do ambiente escolar. O racismo e as discriminações ainda acontecem de maneira clara nas escolas, ele vem por parte dos pais, alunos e até mesmo das equipes diretivas. Para reverter esse quadro crítico que ainda está sendo encontrado nas escolas é preciso de empenho da comunidade em parceria com as escolas podendo assim ter uma mudança significativa não apenas na escola mais na sociedade brasileira em geral. Temos na educação a chave da mudança formando cidadãos que respeitam $\mathrm{e}$ conscientes que o Brasil foi constituído de diversas culturas e tradições cabendo assim a cada um de nós respeitarmos e valorizarmos cada parte da nossa história.
}

Saberes Pedagógicos, Criciúma, v. 3, n³, Edição Especial 2019.- Curso de Pedagogia - UNESC 
Para haver a mudança na educação, segundo Hauça, "a mudança que eu quero que aconteça deve partir de mim mesma me aceitando como mulher negra me valorizando, passando minha cultura e a história do meu povo onde meus alunos possam perceber como tudo isso é parte da história deles também".

Para obter êxito, a escola e seus professores não podem improvisar. Tem que desfazer mentalidade racista e discriminadora secular, superando o etnocentrismo europeu, reestruturando relações étnico-raciais e sociais, desalinhando processos pedagógicos (BRASIL, 2003, p. 501).

Por sua vez, Jeje e Iourubá reforçaram que as mudanças podem e devem ser feitas nas práticas pedagógicas na sala de aula de modo a proporcionar aos alunos um conhecimento que ultrapasse o conteúdo dos livros didáticos. É preciso criar metodologias diferenciadas para contar e trazer essa nova cultura e história para sala de aula. Partindo desta premissa, os alunos poderão vivenciar uma nova prática e metodologia, percebendo que o Brasil é um país onde a diversidade cultural é a "chave" para entender a história. Compreendendo que a luta antirracista deve ser encampada por todos e todas.

Neste sentido:

A relevância do estudo de temas decorrentes a história e cultura afro-brasileira e africana não se restringem á população negra, ao contrário, dizem respeito a todos os brasileiros, uma vez que devem educar-se enquanto cidadãos atuantes no seio de uma sociedade multicultural e pluriétnica, capazes de construir uma nação democrática. (BRASIL, 2003, p. 503).

Durante as entrevistas foi identificado o anseio das educadoras de conseguirem utilizar a educação como ferramenta de mudança, a fim de contribuírem para formação de um país onde todos respeitem e valorizem as diferenças encontradas na sociedade. Ao perceberem a educação desta maneira, podemos constatar que as educadoras aplicam em sua prática pedagógica, metodologias de ensino que permitem a valorização de cada cultura e suas particularidades. Desta maneira, objetivam o uso de formas de ensino diferenciadas das que receberam de seus professores quando estudavam. Acreditam que a partir da sala de aula é possível a construção de uma sociedade onde a discriminação racial não se faz mais forte que o conhecimento. Cumprir a lei contudo, é responsabilidade 
de todos e não apenas do professor em sala de aula. Exige-se, assim, um comprometimento solidário de vários elos do sistema de ensino brasileiro (BRASIL, 2003).

Diante da importância de colocar o conteúdo da Lei no $10.639 \backslash 03$ em prática, as educadoras entrevistadas corroboram que o apoio de toda a comunidade brasileira é indispensável. Reconhecem que deve ainda haver progresso na atuação dos professores e equipe diretivas para que a mudança seja feita e aconteça de maneira que se possa observar concretamente uma melhoria do ambiente escolar. Hauça comenta "o processo é lento e continuo, mas o primeiro passo para mudança já foi vencido com a criação da lei. Agora precisamos batalhar para aplicar todos os dias no ambiente escolar e não apenas nas datas comemorativas."

Em grande parte das escolas do ensino básico as questões sobre diversidade étnico racial e de gênero são, muitas vezes, trabalhadas de acordo da boa vontade e sensibilidade da/o profissional da educação, ou então são discutidos pontualmente apenas em datas comemorativas. Assim, as identidades continuam no campo da invisibilidade e do silenciamento no espaço escolar. (JESUS, 2010, p. 485).

Quando indagada qual mensagem uma mulher negra e docente poderia deixar como forma de contribuição ao movimento feminista negro, e que pudesse contribuir para educação na importância de conhecer e respeitar o e história afro-brasileira, as educadoras forneceram respostas semelhantes que em síntese visam buscar "igualdade" para todos.

Nagô traz como mensagem que "devemos persistir e nunca desistir podemos até perder às vezes, mais isso não pode nós abalar afinal temos a arma mais poderosa em nossas mãos o 'conhecimento' e o dever de levar nossos ensinamentos para buscar uma sociedade melhor." Participando ativamente na formação de novos indivíduos que respeitem as variadas culturas encontradas no Brasil para que não haja mais nenhum tipo de discriminação por haver pessoas diferentes umas das outras."

\footnotetext{
Diante dos estudos sobre a ocupação da carreira docente pelas mulheres negras, conclui-se que elas percebem a profissão como um espaço que permite uma intervenção social e a possibilidade de romper com as desigualdades. Em suas trajetórias, elas lidam com suas identidades, conflitos e dissabores da profissão, guiadas pela convicção da potencialidade transformadora da educação. (JESUS, 2010, p. 485-486).
}

Saberes Pedagógicos, Criciúma, v. 3, n³, Edição Especial 2019.- Curso de Pedagogia - UNESC 
Como resultado da análise de dados nas entrevistas das educadoras negras, suas histórias, a entrada dessas mulheres na educação básica, as dificuldades e preconceitos enfrentados diariamente por ser mulher negra e educadora, constatou-se que cada uma empenha-se na busca dos objetivos da Lei ${ }^{\circ} 10.639 \backslash 03$. Cada educadora mostra sua importância de forma diferente, sempre focadas no futuro, com a esperança de contribuir para o término das diferenças na construção de um país igualitário, desvinculado da cor da pele e história de seus antepassados. Essas mulheres negras valorizam a história de seu povo como peça fundamental da história brasileira. Perpetuam o orgulho de sua cor e a valorização do seu povo na luta para conquista uma sociedade mais justa para todos, sem espaço para o racismo e discriminações raciais.

\section{SOBRE O SIGNIFICADO DA PESQUISA}

Esta pesquisa demonstrou como é difícil ser mulher negra na sociedade brasileira e particularmente na docência. Podemos perceber também que a discriminação racial e o preconceito ainda fazem parte do cotidiano e da realidade destas educadoras conforme relatos sobre suas trajetórias de formação, os quais apontam o dificultoso ingresso na Rede Municipal de Criciúma. O preconceito e a discriminação estão presentes desde a infância das entrevistadas, permanecendo até os dias atuais. Esta condição é motivo pelo qual buscam, através da educação e dos conhecimentos adquiridos com sua formação docente, a mudança de uma triste realidade imposta pela sociedade.

A entrevistada Jeje expõe em suas considerações que:

Não devemos nos culpar por temos nascidos e crescidos negrola mais nos orgulhar de toda nossa conquista e história deixada pelo nosso povo, passar para essa nova geração de indivíduos o orgulho que temos por sermos negros fazendo assim cada vez mais a valorização da nossa história. Somos a mudança que queremos e desejamos então vemos na educação um futuro que saberá valorizar e respeitar a cultura afro brasileira, através dela que o Brasil foi construído, acreditado, e busca por um futuro onde sociedade possa ser livre de qualquer tipo de preconceito e discriminação nascemos todos como um propósito de buscar a vitória não importando ser negro ou branco temos nosso lugar e nossa voz na sociedade brasileira.

Saberes Pedagógicos, Criciúma, v. 3, n³, Edição Especial 2019.- Curso de Pedagogia - UNESC 
Da leitura das entrevistas, podemos concluir que a Lei $\mathrm{n}^{\circ} 10.639 \backslash 03$ sancionada em março de 2003 foi uma conquista para educação da história brasileira. A nova diretriz tornou possível a execução de metodologias diferenciadas capazes de oportunizar aos alunos acesso a história esquecida durante anos, rotineiramente apresentada somente no que tange à desvalorização da cultura afro descente.

Desse modo, as educadores acreditam que com um novo modelo de educação será possível passar a importância da história e da cultura dos negros sem estereótipos e discriminações, mostrando que o Brasil é constituído de diferentes culturas e tradições, havendo espaços e direitos para todos na sociedade. E por fim queremos ressaltar que essas quatro educadoras negras representam a transgressão de uma norma social quando rompem com o racismo e o sexismo e utilizam a educação como um espaço de enfrentamento e luta antirracista.

Após a defesa do artigo, o resultado da pesquisa realizada poderá ser entregue nas escolas da região, a fim de que os mesmos possam ter conhecimento das vivências de profissionais da educação em relação ao ser mulher negra na educação básica brasileira, em particular em escolas municipais de Criciúma.

\section{REFERÊNCIAS}

AZEREDO, Sandra. Teorizando sobre gênero e relações raciais. Revista Estudos Feministas, número especial, p. 203-216, 2. sem. 1994.

BAIRROS, Luiza. Nossos feminismos revisitados. Revista Estudos Feministas. IFCS/UFRJ- PPCIS/UERJ. v.3, n.2, 1995.

BISPO, Silvana Santos. Nós temos que falar sobre nós: populações negras e lugares de fala. Disponível em: http://www.encontro2012.historiaoral.org.br/resources/anais/3/1337109303_ARQUIVO_ HISTORIAORAL-ARTIGO.pdf. Acesso em 14 de maio de 2018.

BRASIL. Lei $\mathbf{N}^{\mathbf{0}} \mathbf{1 0 . 6 3 9} \backslash \mathbf{0 3}$, de março de 2003. Diretrizes Curriculares Nacionais Gerais da Educação Básica. Ministério da Educação. Secretária de Educação Básica. Diretoria de Currículos e Educação Integral. Brasília: MEC, SEB, DICEI, 2003. 


\section{SABERES PEDAGÓGICOS}

Revista do Curso de Graduaçāo de Pedagogia - Unesc

ISSN 2526-4559

CARNEIRO, Sueli. "Enegrecer o feminismo: a situação da mulher negra na América Latina a partir de uma perspectiva de gênero". In: ASHOKA EMPREENDIMENTOS SOCIAIS; TAKANO CIDADANIA (Orgs.). Racismos contemporâneos. Rio de Janeiro: Takano Editora, 2003. p. 49-58.

. Mulheres em movimento. Estudos avançados. 17 (49). Estud. São

Paulo Sept./Dec. 2003. Disponível em:

http://www.scielo.br/scielo.php?script=sci_arttext\&pid=S0103-40142003000300008. Acesso em: 14 mai. 2018.

CRENSHAW, Kimberlè. Documento para o encontro de especialistas em aspectos da discriminação racial relativos ao gênero. Estudos Feministas. Centro de Filosofia e Ciências Humanas, Centro de Comunicação e Expressão, Florianópolis, Santa Catarina, v.7, n. 12, p. 171-188, jan. 2012.

GIACOMINI, Sonia Maria. Mulher e escrava. Petrópolis: Vozes, 1988.

GIL, Antonio Carlos. Métodos e técnicas de pesquisa social. São Paulo: Atlas, 1999.

Como elaborar projetos de pesquisa. 4. ed. São Paulo: Atlas, 2007.

HENRIQUES, Cibele da Silva. Do trabalho doméstico à educação superior: a luta das mulheres trabalhadoras negras pelo direito à educação superior. O Social em Questão Ano XX - n37- Jan.\Abr.2017.

HOOKS, Bell. Intelectuais negras. Estudos feministas de 2014. Disponível em: https://www.geledes.org.br/wp-content/uploads/2014/10/16465-50747-1-PB.pdf. Acesso em: 14 maio 2018.

JESUS. Carla Cristina dos Santos de. Mulheres negras e docência: identidade e trajetória. Fórum Nacional de Crítica Cultural 2 Educação básica e cultura: diagnósticos, proposições e novos agenciamentos 18 a 21 nov. 2010. Disponível em: http://www.poscritica.uneb.br/anais-eletronicos/arquivos/55.pdf. Acesso em: 14 mai. 2018.

SOARES, Vera. "O feminismo e o machismo na percepção das mulheres brasileiras". In: VENTURINI, Gustavo; RECAMAN, Marisol; OLIVEIRA, Suely (Orgs.). A mulher brasileira nos espaços público e privado. 1. ed. São Paulo: Editora e Fundação Perseu Abramo, 2004. p. 161- 182.

Recebido: 15/06/2019

Aprovado: 01/08/2019

Publicado: 20/09/2019 